\title{
Involvement of MMP-12 and phosphodiesterase type 4 in cigarette smoke-induced inflammation in mice
}

\author{
O. Leclerc*\#, V. Lagente*, J-M. Planquois ${ }^{\#,, ~}$, C. Berthelier ${ }^{\#,+}$, M. Artola ${ }^{\#}$, \\ T. Eichholtz ${ }^{\#, \S}$, C.P. Bertrand ${ }^{\#, f}$ and F. Schmidlin ${ }^{\#, \S}$
}

ABSTRACT: The aim of the present study was to characterise a mouse model of airways inflammation induced by cigarette smoke and to compare it with a lipopolysaccharide (LPS) model with regards to the efficacy of a PDE4 inhibitor (cilomilast), a corticosteroid (dexamethasone) and macrophage metalloelastase (MMP)-12 gene deletion.

Cigarette smoke exposure for 3 days induced a time-dependent airway neutrophilia associated with an increased level of keratinocyte-derived chemokine (KC), macrophage inflammatory

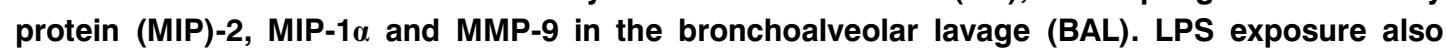
induced an increase in the number of neutrophils in BAL. Studies in MMP-12-/- mice showed that in contrast to the smoking model, MMP-12 did not have a critical role in LPS-induced inflammation. Both cilomilast and dexamethasone blocked LPS-induced neutrophilia in a dose-

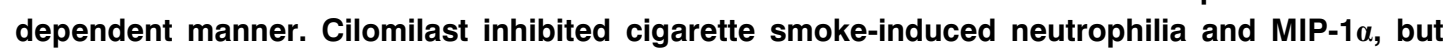
only $10 \mathrm{mg} \cdot \mathrm{kg}^{-1}$ of dexamethasone was effective. Both anti-inflammatory treatments had no effect on the levels of KC and MIP-2 in the BAL.

Although the inflammatory response was very similar in the smoking model and LPS, the pharmacological modulation and the MMP-12 gene deletion highlighted the differences in the mechanisms involved. Furthermore, the cigarette smoke model seemed to better represent the situation described in chronic obstructive pulmonary disease patients.

In conclusion, these differences underline the importance of using an acute smoke-exposure model to investigate potential new treatments for chronic obstructive pulmonary disease.

KEYWORDS: Chronic obstructive pulmonary disease, cigarette smoke, corticosteroid, matrix metalloelastase, phosphodiesterase type 4 inhibitor

hronic obstructive pulmonary disease (COPD) is a disease state characterised by poorly reversible airflow limitation associated with an abnormal inflammatory response of the lung, most commonly as a result of long-term cigarette smoking [1-3]. The pathobiology of COPD includes chronic inflammation in the lung, which contributes to the hallmarks of the disease, i.e. chronic bronchitis, emphysema and a progressive decline in lung function. The inflammatory reaction is characterised by neutrophilia in the bronchoalveolar lavage fluid (BALF) as well as by an increase of pro-inflammatory mediators, such as interleukin (IL)-8 and tumour necrosis factor (TNF)- $\alpha$ [4].

The pathology of COPD may involve the development of emphysema, characterised by a destruction of alveolar septae resulting in airspace enlargement, loss of surface area for gas exchange and loss of elasticity required for efficient contraction of the lung during the breathing cycle [4]. It is believed that the development of emphysema reflects a relative excess of cell-derived proteases, including serine proteases such as neutrophil elastase and matrix metalloproteinases (MMPs) [4], which degrade the connective tissue of the lung, and a relative paucity of antiproteolytic defences. Macrophage metalloelastase (MMP-12) and gelatinase B (MMP-9), which are mainly produced by inflammatory cells, belong to the MMP-family of $\mathrm{Zn}^{2+}$ dependent and $\mathrm{Ca}^{2+}$-dependent proteinases [5], and both seem to play a predominant role in the pathogenesis of COPD and particularly in emphysema. MMP-12 is able to degrade different substrates among which elastin is the major constituent of the alveolar wall. MMP-9 is able to hydrolyse both gelatin and native elastin. More recently, an increase of MMP-9 and MMP-12
AFFILIATIONS

*INSERM U620, Faculté de

Pharmacie, Université de Rennes 1 , Rennes,

\#Pfizer Global R\&D, Fresnes

Laboratories, Fresnes, and

${ }^{+}$Sanofi-Aventis R\&D, Paris, France.

"EliLilly R\&D, Indianapolis, IN, USA.

${ }^{\S}$ AstraZeneca R\&D, Loughborough, and

${ }^{f}$ AstraZeneca R\&D, Alderley Park, Macclestield, UK.

CORRESPONDENCE

$\mathrm{V}$. Lagente

INSERM U620

Université de Rennes 1, 2

avenue du Professeur Léon Bernard 35043 Rennes cedex

France

Fax: 33223234794

E-mail: vincent.lagente@univ-

rennes1.fr

Received:

July 012005

Accepted after revision:

February 132006

SUPPORT STATEMENT

This study received financial support from Pfizer Global Research and Development (Fresnes, France).

European Respiratory Journa Print ISSN 0903-1936

Online ISSN 1399-3003 
levels in the bronchoalveolar lavage (BAL) from COPD patients has been reported $[6,7]$. Knockout mice deficient in the gene encoding MMP-12 (MMP-12-/-) show a diminished inflammatory response to cigarette smoke and are largely resistant to the development of emphysema [8].

Presently, only a few therapies are available for COPD, with limited efficacy. These include bronchodilators, such as anticholinergics. Unlike in asthma, the use of inhaled glucocorticoids in the treatment of COPD is limited. While significant improvements have been reported in the frequency of exacerbations and quality of life [9], no clinical benefit in either lung function or symptom scores has been shown. In most studies [10-12], with the exception of the study by TASHKIN et al. [13], inflammatory indices such as sputum neutrophilia and sputum mediators (e.g. IL- 8 and TNF- $\alpha$ ) did not change in response to treatment with glucocorticoids. This suggests that glucocorticoids have, at least in the short term, little anti-inflammatory effect in this group of patients and, therefore, that the inflammatory process in COPD is resistant to glucocorticoids. Therefore, new anti-inflammatory drugs are needed to improve the control of symptoms and to prevent the progression of COPD.

Such drugs may include inhibitors of phosphodiesterases (PDE), mainly selective PDE4 inhibitors that inactivate cyclic adenosine monophosphate. Indeed, PDE4 is the predominant PDE isoenzyme expressed in the inflammatory cells. The second generation of specific PDE4 inhibitors, exemplified by cilomilast, has been shown to possess anti-inflammatory effects in vitro [14], in vivo [15] and in COPD clinical trials where 6 weeks of treatment improves lung function such as forced expiratory volume in one second [16]. Additional candidate drugs include inhibitors of MMPs [5].

To date, only a few animal models of COPD have been developed that could be used to evaluate candidate therapeutic compounds or to identify new targets. The present study was set up to develop an acute model of cigarette smokeinduced inflammation in mice, which could highlight some of the key features of the inflammatory response observed in COPD patients. To further validate the model, the involvement of MMP-12 in the development of airway inflammation was confirmed. Furthermore, the current authors studied the effects of a glucorticosteroid (dexamethasone) and a PDE4 inhibitor (cilomilast), which are representatives of two classes of drugs used in clinical trials in COPD. The smoking model was sensitive to cilomilast, but largely resistant to the effects of dexamethasone, which reflects the observations made in clinical trials with other glucocorticoids, notably prednisolone and fluticasone [17], and cilomilast itself [15]. Further confirmation of its value was obtained by comparing it with the classical model of neutrophilic inflammation in the lung using inhaled exposure to lipopolysaccharide (LPS). In the LPS model, both cilomilast and dexamethasone were active and gene deletion of MMP-12 had no effect.

\section{MATERIALS AND METHODS}

\section{Animals}

Male $\mathrm{C}_{57} \mathrm{Bl}_{6} / \mathrm{J}$ mice, aged 7 weeks, were purchased from CERJ (Le Genest Saint Isle, France) and quarantined for 1 week before experiments. MMP-12-/- mice were obtained from
Charles River laboratories (Wilmington, MA, USA) following a transfer from Washington University School of Medicine (St Louis, MO, USA) and rederivation on $\mathrm{C}_{57} \mathrm{Bl}_{6}$ background. $\mathrm{C}_{57} \mathrm{Bl}_{6} / \mathrm{J}$ mice were used as wild-type control (WT) mice. Animals were handled in accordance with standards established by the European Animal Welfare acts.

\section{Cigarette smoke exposure}

Mice were exposed to the whole smoke of two Kentucky 1R3 cigarettes once or twice a day for 1, 2 or 3 days or to laboratory air (control mice). Mice were placed in a Plexiglas chamber covered by a disposable filter (Ingenia, Ivry, France). The smoke was produced by the burning of cigarettes and was introduced into the chamber with a constant airflow generated by a mechanical ventilator (7025; Ugo Basile, Comerio, Italy) at a rate of $25 \mathrm{~mL} \cdot \mathrm{min}^{-1}$.

\section{LPS exposure}

The mice were placed in a Plexiglas chamber and were exposed to $100 \mu \mathrm{g} \cdot \mathrm{mL}^{-1}$ LPS for $1 \mathrm{~h}$ or to the vehicle $(\mathrm{NaCl}$, $0.9 \%$; control mice), as previously described [18], delivered using a small particle aerosol generator (SPAG-2 6000 series; ICN Pharmaceuticals Inc., Irvine, CA, USA).

\section{$B A L$}

Mice were anaesthetised by i.p. injection of sodium pentobarbital $\left(60 \mathrm{mg} \cdot \mathrm{kg}^{-1}\right) 16 \mathrm{~h}$ after LPS challenge or the last cigarette smoke exposure. Airspaces were washed using six times $0.3 \mathrm{~mL}$ of PBS solution, kept at $37^{\circ} \mathrm{C}$. The samples collected were dispatched in two fractions. The first $(0.6 \mathrm{~mL}$ corresponding to the first two lavages) was used for mediator measurement and the second for the cell determination $(0.9 \mathrm{~mL})$. The first fraction was centrifuged $(600 \times g$ for $10 \mathrm{~min})$ and kept at $-80^{\circ} \mathrm{C}$ until mediator determination. The cell pellet was then resuspended in $0.6 \mathrm{~mL}$ PBS, pooled with the second fraction and maintained at $4^{\circ} \mathrm{C}$ until cell determination.

\section{Cell count and determination}

Total cell count in BALF was determined using a particle counter (Z2 Coulter; Beckman Coulter, Miami, FL, USA). Differential cell counts were performed on cytospin preparations (Cytospin 3; Thermo Shandon, Waltham, MA, USA) after staining with May-Grünwald-Giemsa stain (Sigma chemical, St Louis, MO, USA).

\section{Mediator measurements}

Keratinocyte-derived chemokine $(\mathrm{KC})$, macrophage inflammatory protein (MIP)-2 and MIP-1 $\alpha$ levels in BALF were determined using ELISA assay kits (Quantikine M Murine; R\&D system, Minneapolis, MN, USA) according to the manufacturer's instructions. MMP levels in BALF were determined by gelatin zymography.

\section{Drug administration to mice}

Dexamethasone $\left(0.5-10 \mathrm{mg} \cdot \mathrm{kg}^{-1}\right)$ or cilomilast $\left(3-100 \mathrm{mg} \cdot \mathrm{kg}^{-1}\right)$ were suspended in methylcellulose (MC) $0.5 \%$ (weight/ volume) and administered orally $\left(20 \mathrm{~mL} \cdot \mathrm{kg}^{-1}\right)$. Control mice received $0.5 \% \mathrm{MC}$ only. Treatments were performed $1 \mathrm{~h}$ before LPS, smoke or control exposure. 


\section{Materials}

LPS (from Escherichia coli, serotype 055:B5), Tris buffer, Coomassie stain solution, dexamethasone 21-phosphate and MC were purchased from Sigma chemical. Kentucky 1R3 cigarettes (Tobacco Health Research) were provided by the University of Kentucky (Lexington, KY, USA). Sodium pentobarbital was obtained from Sanofi Santé Animal (Libourne, France). PBS solution was from Dulbecco's (Gibco, Paisley, UK). Standards for zymography and gelatin were obtained from BioRad (Hercules, CA, USA). Triton X-100 was from ICN Pharmaceuticals Inc.

\section{Statistical analysis}

Comparisons were made by ANOVA. The results were expressed as mean \pm SEM. Analysis of treatment effects across the various groups was performed using a two-way ANOVA. Comparison of treatment interaction was realised by Fisher's exact tests. For each analysis, p-values $<0.05$ were considered to be statistically significant.

\section{RESULTS}

Effect of cigarette smoke exposure on the development of airway inflammation

$\mathrm{C}_{57} \mathrm{Bl}_{6} / \mathrm{J}$ mice exposed to two cigarettes once a day showed a moderate increase in the number of neutrophils in the BALF after only 3 days of consecutive smoke exposure (fig. 1a). In contrast, exposure of mice to two cigarettes twice a day elicited a marked and significant neutrophil influx in the BALF that appeared after 2 days, and was further increased after 3 days of exposure (fig. 1b). In the latter protocol, a moderate, but significant increase in the number of eosinophils was also noted after 2 and 3 days of smoke exposure, whereas the number of macrophages and lymphocytes were unchanged. All further data were obtained in the 3-day model.

Using ELISA, it was found that KC, MIP- $1 \alpha$ and MIP-2 were markedly increased in the BAL fluid of mice exposed to cigarette smoke from $3 \pm 0.5$ to $45 \pm 16 \mathrm{pg} \cdot \mathrm{mL}^{-1}(\mathrm{p}<0.01)$, from $1 \pm 0.1$ to $13 \pm 7 \mathrm{pg} \cdot \mathrm{mL}^{-1}(\mathrm{p}<0.05)$ and from $0.5 \pm 0.5$ to $17.7 \pm 4.7$ $\mu \mathrm{g} \cdot \mathrm{mL}^{-1}(\mathrm{p}<0.01)$, respectively.

Using zymography, three bands corresponding to gelatinase activities of $130 \mathrm{kDa}, 96 \mathrm{kDa}$, and $88 \mathrm{kDa}$ were observed (fig. 2a) in the BALF from smoking mice compared with control mice. These bands were not present after treatment of the gel with $10 \mathrm{mM}$ EDTA (data not shown) suggesting that these bands corresponded to metalloproteases. The activities observed at $96 \mathrm{kDa}$ and $88 \mathrm{kDa}$ may correspond to MMP-9 pro- (latent) and active forms. The analysis of the intensity of the spot by densitometry showed a marked and significant increase in the pro- and active form of MMP-9 in mice exposed to cigarette smoke after 3 days in comparison to control (laboratory air-exposed) mice (fig. 2b).

\section{Effect of cigarette smoke exposure in MMP-12-/- mice}

Figure 3 shows the effects of exposure to cigarette smoke in MMP-12-/- and WT mice. As previously observed in $\mathrm{C}_{57} \mathrm{Bl}_{6} / \mathrm{J}$, cigarette smoke exposure (two cigarettes, twice a day) to WT mice elicited an increase of neutrophils after 2 and 3 days of exposure. In contrast, in MMP-12-/- mice, the neutrophil influx was significantly reduced after both 2 and 3 days of smoke exposure. A nonsignificant reduction was noted on the
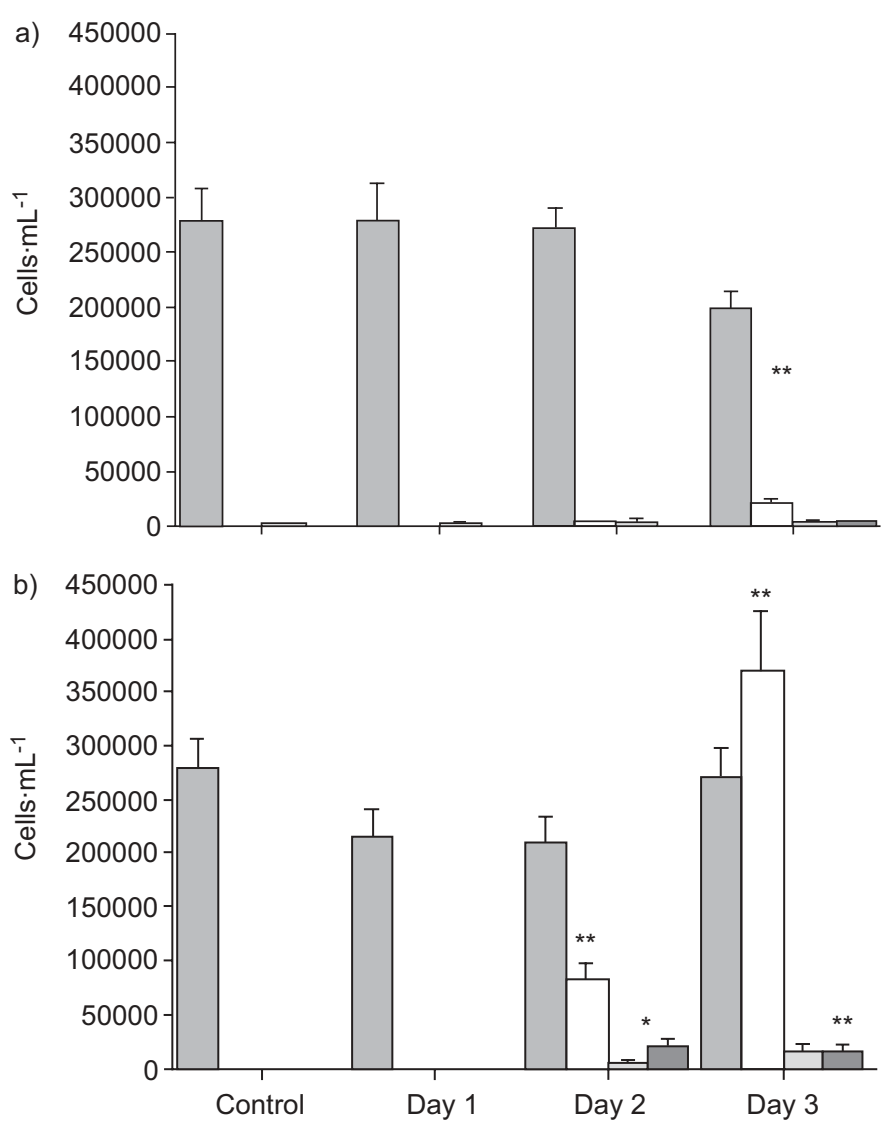

FIGURE 1. Time course of inflammatory cell recruitment in the bronchoalveolar lavage (BAL) of $\mathrm{C}_{57} \mathrm{Bl}_{6} / \mathrm{J}$ mice after cigarette smoke exposure or laboratory air (control mice). a) Two cigarettes once a day and b) two cigarettes twice a day. $\square$ : macrophages; $\square$ : neutrophils; $\square$ : lymphocytes; $\square$ : eosinophils. Each of these was determined by morphometric analysis under microscopic examination. No difference in the number of cells in the BAL of control mice was noted throughout the experiment. Data are presented as mean \pm SEM. $n=8 . *: p<0.05$ versus control; $\star *: p<0.01$.

increased eosinophilia. Using zymography, an important decrease of MMP-9 activity was observed in MMP-12-/- mice after smoke exposure compared with the WT mice (fig. 4). The relative intensity of the pro-MMP-9 in MMP-12-/- mice exposed to cigarette smoke appeared equivalent to that in the control mice exposed to laboratory air.

To investigate whether the deletion of MMP-12 affected the general ability of the mice to respond to an inflammatory stimulus involving neutrophil influx, the effect of exposure to LPS by aerosol on WT and MMP-12-/- mice was investigated. LPS exposure elicited a marked enhancement in the number of neutrophils in both WT and MMP-12-/-, which was not significantly different $\left(3.43 \pm 1.47\right.$ and $4.25 \pm 0.91$ cells $\times 100,000 \cdot \mathrm{mL}^{-1}$, respectively), suggesting that MMP-12 is specifically involved in smoke-induced inflammation.

\section{Effect of dexamethasone and cilomilast on lung inflammation induced by cigarette smoke exposure}

Treatment of mice with 2.5 or $5 \mathrm{mg} \cdot \mathrm{kg}^{-1}$ dexamethasone did not significantly reduce the increase in neutrophil number in the BAL of mice after 3 days of cigarette smoke exposure (fig. 5a). 
a)

\section{Control}

Smoke

1

3

4

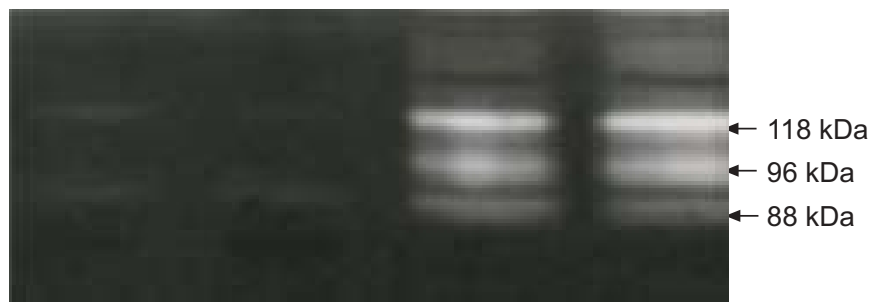

b)

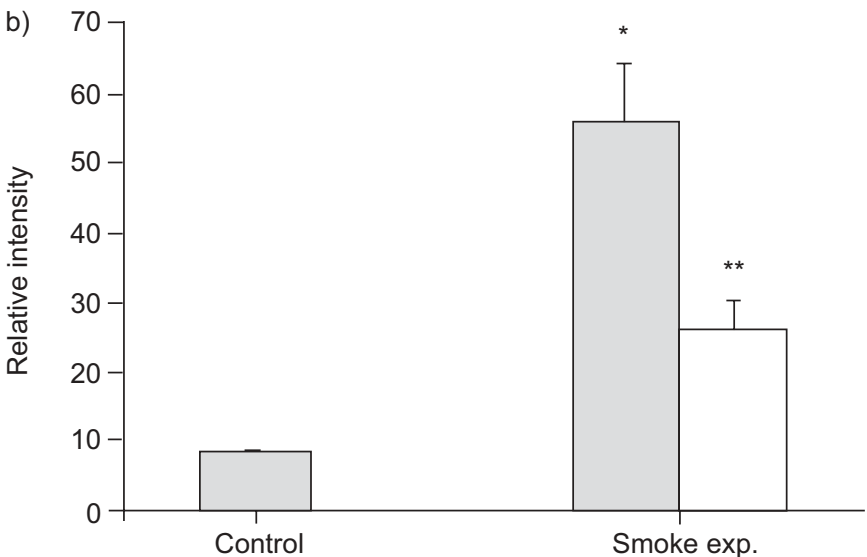

FIGURE 2. Zymographic analysis of the bronchoalveolar lavage (BAL) of $\mathrm{C}_{57} \mathrm{BI}_{6} / \mathrm{J}$ mice after two cigarettes twice a day for 3 days of smoke exposure (exp.). a) BAL from two control mice (lanes 1 and 2) and BAL from two mice exposed to cigarette smoke (lanes 3 and 4). The zymography is representative of three independent experiments. b) Relative intensity of the bands at $96 \mathrm{kDa}$ metalloelastase (MMP)-9 $(\square)$ and 88 kDa MMP-9 $(\square)$. Data are presented as mean \pm SEM. $n=6 .{ }^{*}: p<0.05$ versus control; **: $p<0.01$.

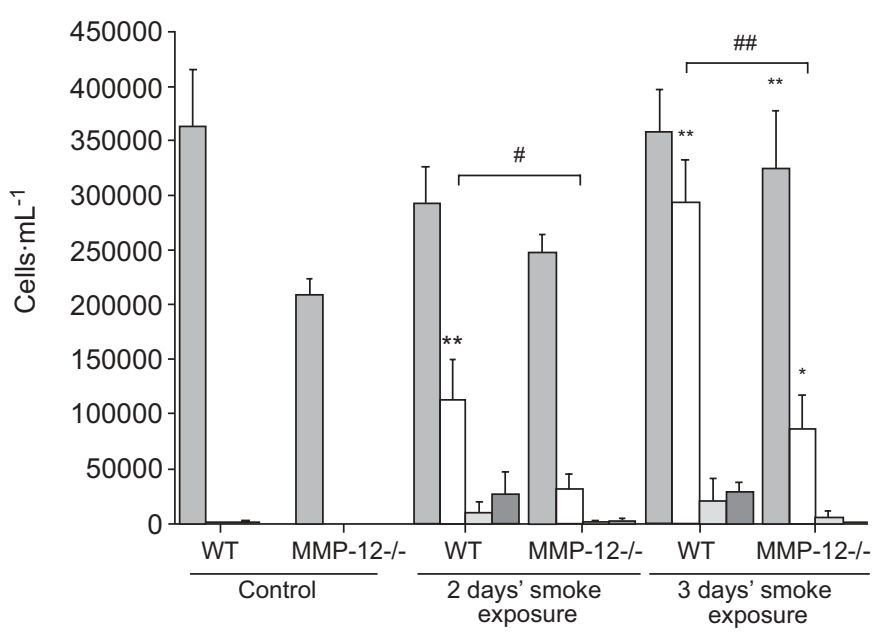

FIGURE 3. Time course of inflammatory cell recruitment in the bronchoalveolar lavage (BAL) of wild-type (WT) or metalloelastase (MMP)-12-/- mice after exposure of two cigarettes twice a day or laboratory air (control mice). No difference in the number of cells in the BAL of control mice were noted throughout the experiment.

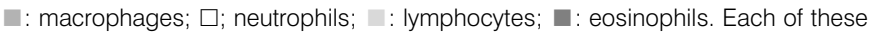
was determined by morphometric analysis under microscopic examination. Data are presented as mean \pm SEM. $n=8 .{ }^{\#}: p<0.05$ versus WT; ${ }^{\# \#}: p<0.01$ versus WT; $*: p<0.05 ; * *: p<0.01$ versus control. a)
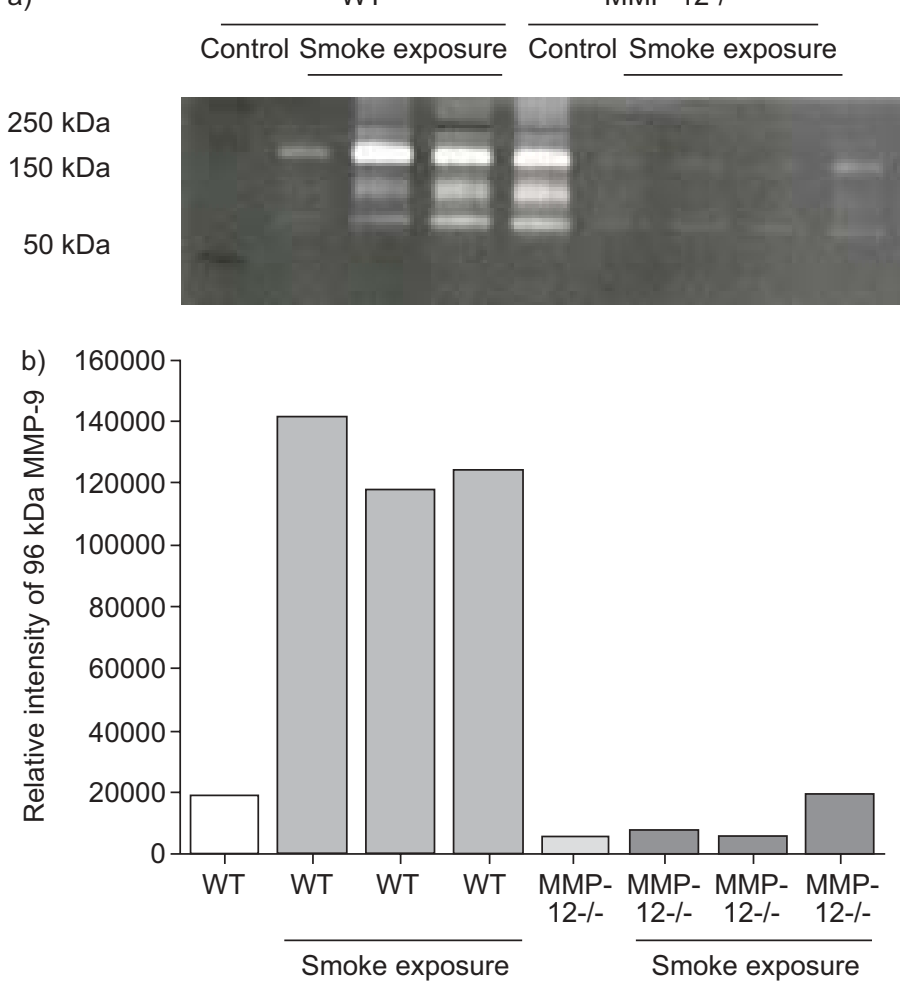

FIGURE 4. a) Zymography of the bronchoalveolar lavage fluid of wild-type (WT) and metalloelastase (MMP)-12-/- mice exposed to cigarette smoke from two cigarettes twice a day for 3 days or laboratory air (control mice). b) The relative intensity of the $96 \mathrm{kDa}$ MMP-9. $\square$ : control WT; $\square$ : WT smoke exposure; $\square$ : MMP12-/- control; $\square:$ MMP-12-/- smoke exposure. Data shown are representatives of three experiments.

Only a moderate, but significant reduction of neutrophil influx was noted at the highest dose of dexamethasone $\left(10 \mathrm{mg} \cdot \mathrm{kg}^{-1}\right)$. However, treatment with dexamethasone elicited a complete inhibition of the eosinophil influx at all concentrations tested (fig. 5a). Cilomilast $\left(3,10\right.$ or $30 \mathrm{mg} \cdot \mathrm{kg}^{-1}$ ) prevented the neutrophil influx induced by cigarette smoke exposure in a dose-dependent manner (fig. 5b). Cilomilast (3 and $30 \mathrm{mg} \cdot \mathrm{kg}^{-1}$ ) also reduced the eosinophil influx.

The levels of MIP1- $\alpha$ were markedly increased in the BALF of mice exposed to cigarette smoke after 3 days in comparison with control mice (fig. 6). Interestingly, cilomilast, but not dexamethasone, was able to prevent the increase of MIP1- $\alpha$ levels in a dose-dependant manner (fig. 6), whereas KC and MIP-2 were not affected by either even at the highest dose (data not shown).

\section{Effect of dexamethasone and cilomilast on neutrophil influx by LPS exposure}

To compare the potential anti-inflammatory role of dexamethasone and cilomilast in the smoking model to that in a well-known airway inflammatory model, the potency of both treatments on neutrophil influx in the BAL fluid of $\mathrm{C}_{57} \mathrm{Bl}_{6} / \mathrm{J}$ mice upon exposure to LPS was investigated (fig. 7). In contrast to the observations in the smoking model, neutrophilia in the LPS model was sensitive to all concentrations of 

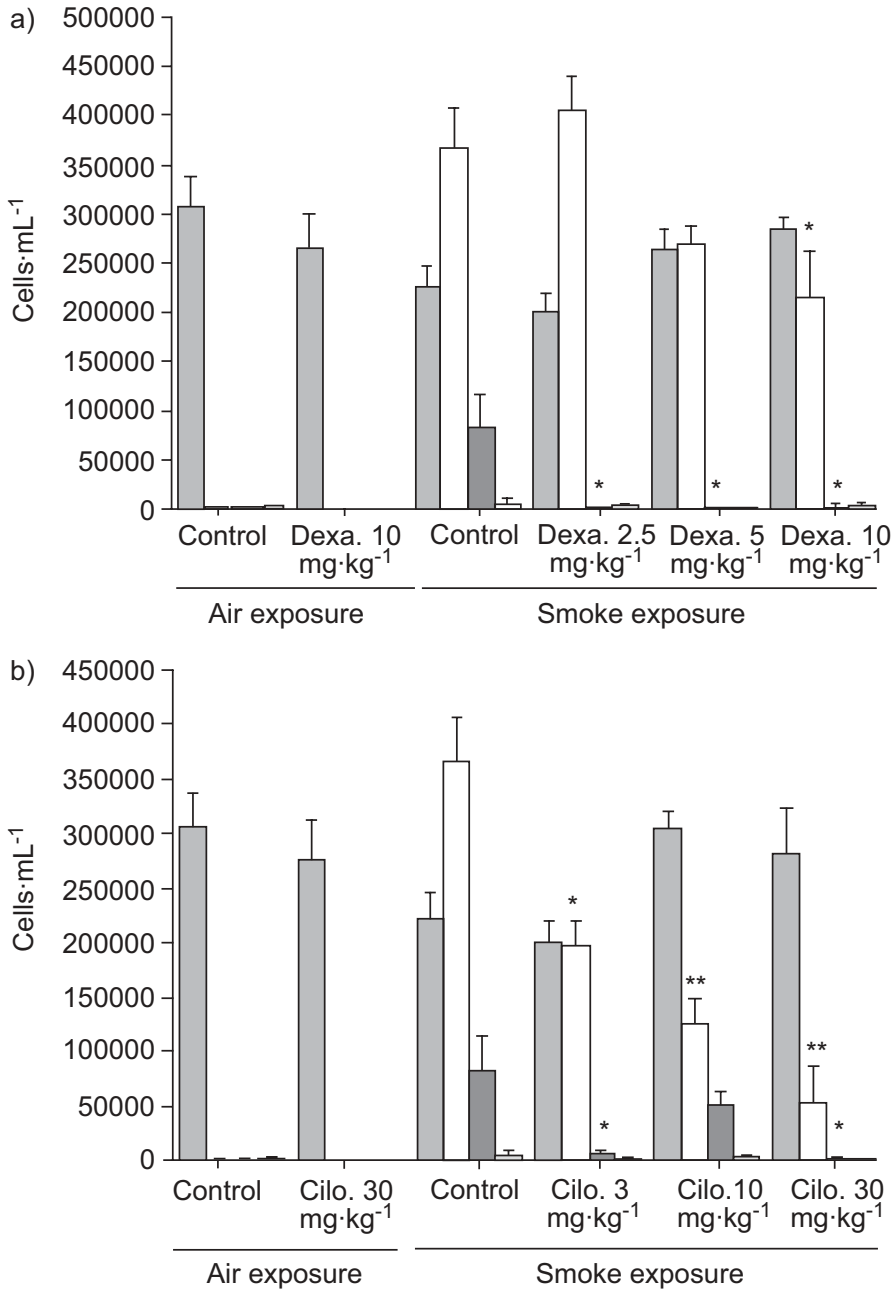

FIGURE 5. Dose-response effect of a) dexamethasone (dexa.; 2.5, 5 and $10 \mathrm{mg} \cdot \mathrm{kg}^{-1}$ ) and b) cilomilast (cilo.; 3, 10 and $30 \mathrm{mg} \cdot \mathrm{kg}^{-1}$ ) on cigarette smokeinduced inflammatory cell recruitment in bronchoalveolar lavage of $\mathrm{C}_{57} \mathrm{Bl}_{6} / \mathrm{J}$ mice. Mice were exposed to smoke from two cigarettes twice a day for 3 days or laboratory air (control mice). $\square$ : macrophages; $\square$ : neutrophils; $\square$ : eosinophils; 1 : lymphocytes. Each of these was determined by morphometric analysis. Data are presented as mean \pm SEM. $n=8 . *$ : $p<0.05 ;{ }^{*}: p<0.01$ versus vehicle.

dexamethasone tested $\left(0.5,1,2.5\right.$ and $\left.5 \mathrm{mg} \cdot \mathrm{kg}^{-1}\right)$ as well as to cilomilast $\left(10,30,60\right.$ and $\left.100 \mathrm{mg} \cdot \mathrm{kg}^{-1}\right)$. The effect of dexamethasone was already noted with the dose of $0.5 \mathrm{mg} \cdot \mathrm{kg}^{-1}$ with a maximum inhibition already achieved at $2.5 \mathrm{mg} \cdot \mathrm{kg}^{-1}$. Cilomilast reduced neutrophilia after LPS exposure with similar efficacy to the cigarette smoke exposure experiments.

\section{DISCUSSION}

The present study reports the development of an acute model of cigarette exposure in mice, in which a marked neutrophila developed after 2-3 days. This airway inflammation was sensitive to MMP-12 gene deletion and the PDE4 inhibitor cilomilast, but largely insensitive to the glucocorticoid dexamethasone. Therefore, it was significantly different from the traditional model of neutrophilic lung inflammation using inhalation of LPS, which was sensitive to both cilomilast and dexamethasone, but in which MMP-12 deletion had no effect.
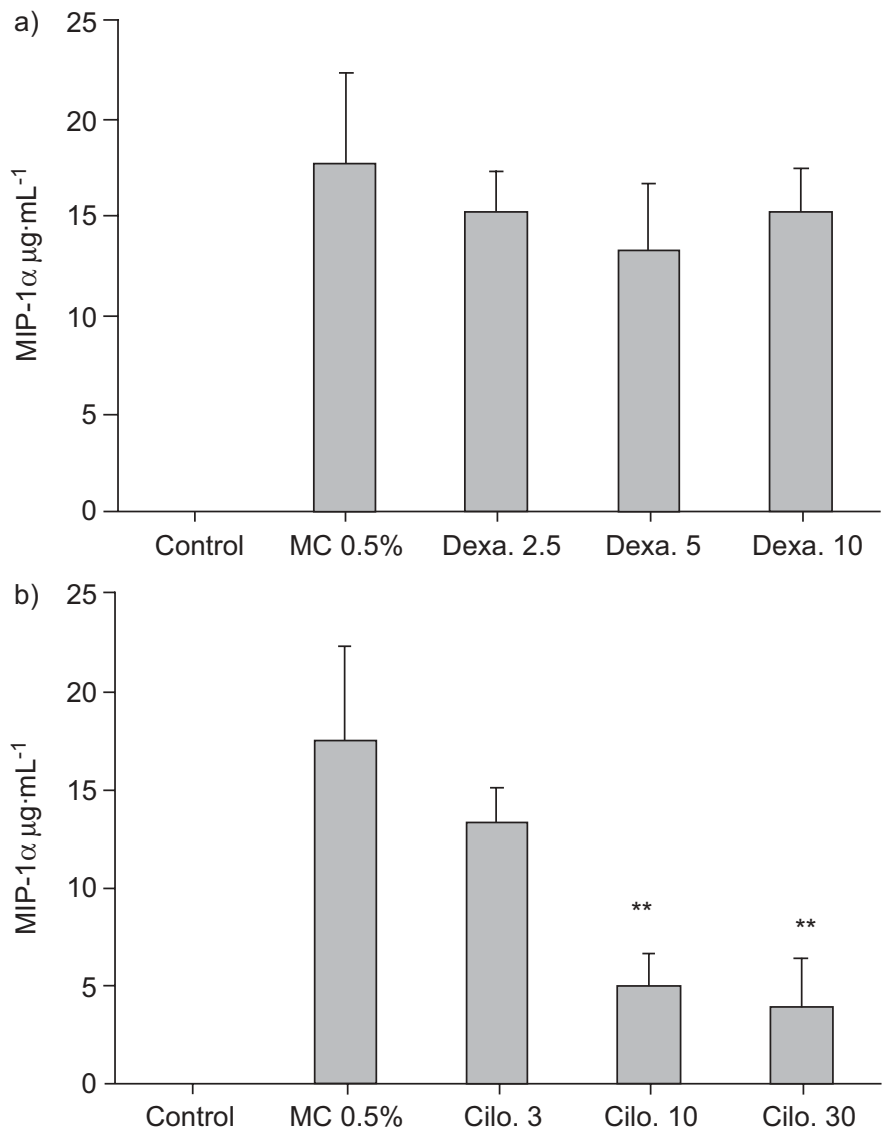

FIGURE 6. Dose-response effect of a) dexamethasone (dexa.; 2.5, 5 and $10 \mathrm{mg} \cdot \mathrm{kg}^{-1}$ ) and b) cilomilast (cilo.; 3,10 and $30 \mathrm{mg} \cdot \mathrm{kg}^{-1}$ ) on cigarette smoke exposure-induced MIP-1 $\alpha$ increase in bronchoalveolar lavage fluids of $\mathrm{C}_{57} \mathrm{Bl}_{6} / \mathrm{J}$ mice. Mice were exposed to smoke from two cigarettes twice a day for 3 days or laboratory air (control). Methylcellulose (MC) $0.5 \%$ is the vehicle of dexa. and cilo. Data are presented as mean \pm SEM. $n=8 . * *: p<0.01$ versus control+mice.

Cigarette smoking is the prevalent predisposing factor to chronic bronchitis, emphysema and COPD. However, the mechanisms by which exposure of the lung to cigarette smoke causes the inflammatory process and pathological alterations of the tissue seen in COPD are not completely understood. Glucocorticoids are commonly used for the treatment of COPD and show benefits in particular on frequency and severity of exacerbations [19, 20]. However, most studies suggest that there is little evidence of significant anti-inflammatory activity with regards to neutrophils or macrophages [17], although there is an effect on tissue mast cells [21]. Data exist on inhibitors of PDE4, suggesting that the anti-inflammatory activity is limited to CD8+ and CD68+ cells in tissue [15].

The development of new therapies for COPD is hindered due, in part, to the lack of relevant animal models that could be used for increasing current understanding of the inflammatory mechanisms and the study of new candidate drugs. Although cigarette smoke is the most relevant stimulus to reproduce pathology seen in human COPD disease, the length of time required to induce significant emphysematous changes limits the usefulness of such an emphysema model as a pharmacological screening tool. As an alternative, acute models that 

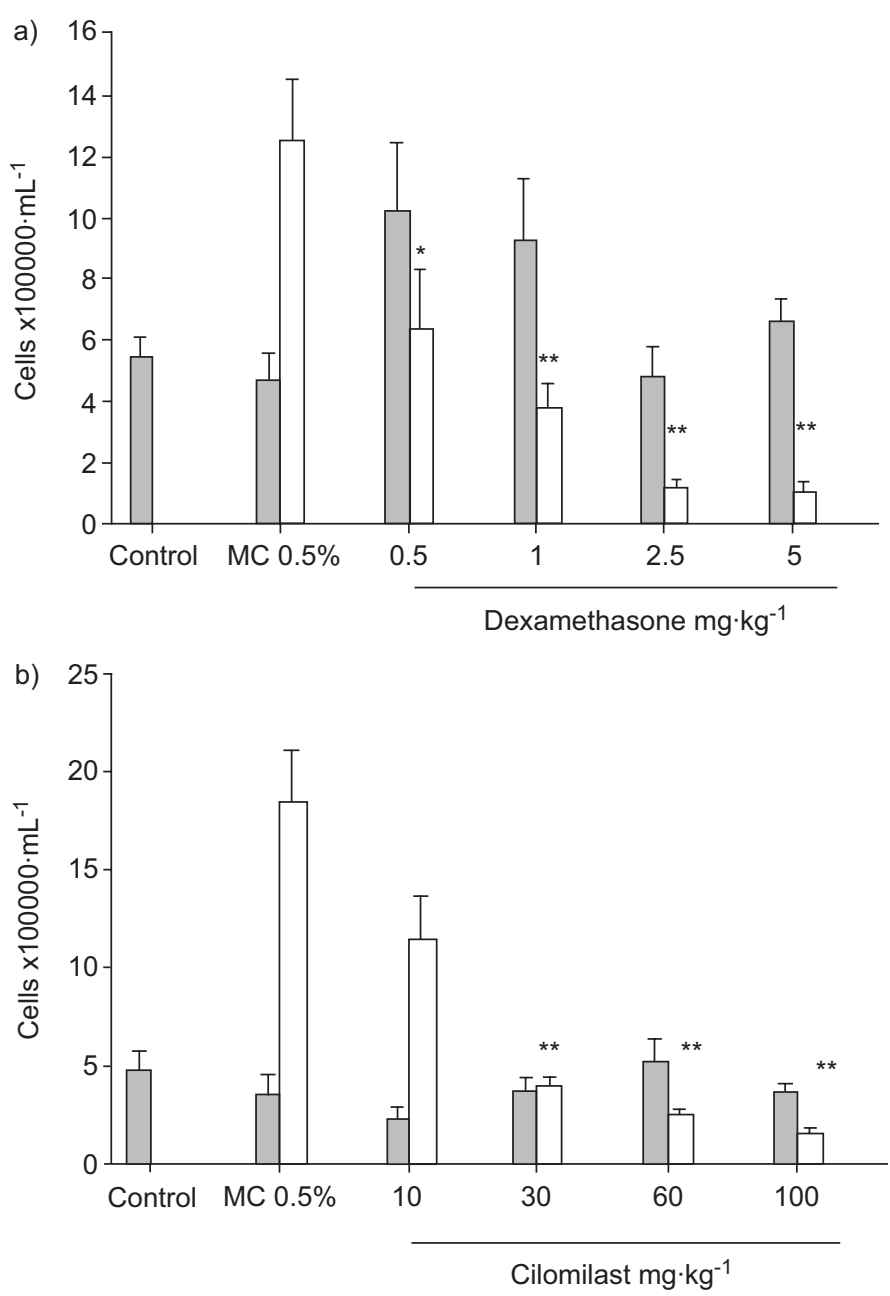

FIGURE 7. Dose-response effect of a) dexamethasone $(0.5,1,2.5$ and $\left.5 \mathrm{mg} \cdot \mathrm{kg}^{-1}\right)$ and b) cilomilast (10,30, 60 and $100 \mathrm{mg} \cdot \mathrm{kg}^{-1}$ ) on lipopolysaccharide (LPS; $100 \mu \mathrm{g} \cdot \mathrm{mL}^{-1}$ for $60 \mathrm{~min}$ ) inducing neutrophil recruitment in bronchoalveolar lavage of $\mathrm{C}_{57} \mathrm{~B}_{6} / \mathrm{J}$ mice. Control mice were treated with the vehicle of LPS ( $\mathrm{NaC}$ $0.9 \%$ ). $\square$ : macrophages; $\square$ : neutrophils. Methylcellulose (MC) $0.5 \%$ is the vehicle of dexamethasone and cilomilast. Data are presented as mean \pm SEM. $n=10$. $*: p<0.05 ; * *: p<0.01$ versus vehicle.

reflect the early inflammatory response to cigarette smoke may provide a first step in the selection of candidate mechanisms and drugs [21].

Therefore, the present study was designed to set up an acute model of cigarette smoke-induced inflammation in mice to investigate mechanisms of COPD and to test candidate drugs. The read-out was focused on cell influx in BAL, cytokine levels and MMP activity, all of which are already employed in clinical trials, and compared the smoking model to a model of LPS inhalation. However, the effects on lung tissue cells, mucous/goblet cell staining and general histopathology were not quantified, and there should not be general statements about the inflammatory status in this model.

The present study shows that once a day exposure to two cigarettes was largely without effect, but exposure to smoke from two cigarettes twice a day for 3 days elicited a dramatic influx of neutrophils in the BALF. In addition, an increase in eosinophils and lymphocytes was observed. Although no increase in macrophages was observed in the BAL, phenotypical changes of lung macrophages suggested an enhanced state of activation and are the subject of further study (data not shown). The inflammatory cell recruitment was associated with an increased level of the chemokines MIP1- $\alpha, \mathrm{KC}$ and MIP-2, which have been involved in the chemotaxis and activation of neutrophils and monocytes [22]. A similar pattern of cellular inflammation has been reported in the BALF and sputum $[23,24]$ of COPD patients, while IL- 8 is increased in induced sputum [11]. IL-8 is a human ligand for CXCR-1/2 and as such an equivalent of $\mathrm{KC}$ in mice.

MMP-9 is elevated in the BALF of subjects with emphysema, suggesting that MMP-9 may be important in the pathogenesis of the disease [25]. These observations have been supported and extended by Russell et al. [6], who showed that more MMP-9 was secreted from macrophages from COPD patients compared with macrophages from healthy volunteers when stimulated with IL-1 $\beta$, endotoxin or cigarette smoke-conditioned medium. In the current experimental model, it was also found that MMP-9 activity was increased. This increased activity may be linked to activation of macrophages and/or the neutrophil influx as previously suggested in studies involving LPS-exposed mice [26].

Cigarette smoke exposure in mice is associated with MMP-12 expression in macrophages and the development of emphysema [27]. Moreover, MMP-12-/- mice exposed to cigarette smoke for 6 months demonstrated a central role for MMP-12 in cell recruitment and the development of emphysema [8]. In an acute model of smoke exposure, neutrophil influx in BALF, desmosine and hydroxyproline (markers for elastin and collagen breakdown, respectively) were greatly reduced in MMP-12-/- mice as compared with control mice [28]. In the present study, this observation was confirmed using the smoke exposure protocol that the authors developed. Interestingly, a very marked reduction of MMP-9 activity in BAL fluid was also observed, suggesting that the increase in MMP-9 activity in response to cigarette smoke depends almost entirely on MMP-12 expression. In contrast to the observations in the smoking model, MMP-12-/- mice developed a similar airway neutrophilia when exposed to LPS as WT mice. This indicates clear differences between the two models and that the early inflammatory process after cigarette smoke exposure, although similar in profile, has different causal mechanisms than the LPS-induced inflammation.

Several clinical trials have been performed using glucocorticoids and PDE4 inhibitors in COPD patients. The clinical benefits of glucocorticoids were mainly limited to effects on exacerbations, while in the majority of studies no effect was seen on inflammatory cell numbers in induced sputum, specifically neutrophils, and on IL-8 levels and MMP-9 activity [10-12]. Ex vivo studies on cells from COPD patients [6] suggest that the inflammatory response seen in COPD may at least in part be resistant to glucocortocoids. More limited data are available on the effects of inhibition of PDE4 in humans, but clinical trials reported an improvement in lung function after treatment with cilomilast in COPD patients [16] and in a small study it was shown to have anti-inflammatory effects in 
biopsies [15]. Ex vivo studies with cilomilast suggest a potent anti-inflammatory effect [29] on cytokine expression.

Glucocorticoids, as well as PDE4 inhibitors, have been reported to be potent anti-inflammatory compounds in vitro and in vivo in various animal models [30]. To establish the importance of the smoking model in predicting efficacy in human disease, the current authors tested representatives from these two drug classes, dexamethasone and cilomilast, in the experimental model and compared it with the LPS model. Neutrophilic inflammation in both models is sensitive to the PDE4 inhibitor cilomilast, but while the LPS model is very sensitive to treatment with the glucocortocoid dexamethasone, neutrophilia in the smoking model is largely insensitive up to concentrations of $10 \mathrm{mg} \cdot \mathrm{kg}^{-1}$, which is the upper tolerated limit for use in mice. It is difficult to explain the difference of the inflammatory process induced by LPS or cigarette smoke. Various hypotheses regarding the involvement of different resident cells and/or pro-inflammatory mediators may be proposed. Experiments in vitro are in progress to dissect the cellular signalling induced by either cigarette smoke condensate or LPS.

An increase of MIP-1 $\alpha$ chemokine was found after cigarette smoke and a significant reduction after the treatment with cilomilast, but not with dexamethasone, which agrees with the data on neutrophilia and suggests a possibly critical role of MIP- $1 \alpha$ in cigarette smoke-induced neutrophil influx.

One hypothesis for the lack of efficacy of the glucocorticoid in the smoking model suggests that oxidative stress generated by cigarette smoke inhibits the anti-inflammatory activity of the glucocorticoid receptor [4]. In addition, it is known that glucocorticoids may prolong neutrophil survival. Further work is required to investigate the causes of steroid insensitivity in the smoking model. It is of interest to note that the relatively modest eosinophilic inflammation seen in the model did respond to treatment with corticosteroids, suggesting a neutrophil- rather than a glucocorticoid-specific effect. A similar hypothesis has been proposed for the reduced steroid sensitivity seen in severe asthma [31].

In conclusion, the current authors have developed an acute smoking mouse model, in which several features of the airway inflammation observed in COPD patients were observed. The present authors report that cigarette smoke-induced inflammation was reduced by the PDE4 inhibitor cilomilast, but was largely unresponsive to the glucocorticoid dexamethasone. Thus, the smoking model shows significant differences with, and potential advantages over, the traditional model of airway neutrophilia using LPS, as was highlighted by the differences in response to gene deletion of MMP-12.

Therefore, this model may be used to explore the inflammatory mechanisms induced by cigarette smoke, the efficacy of new compounds and for the discovery of potential new targets for drug discovery in chronic obstructive pulmonary disease.

\section{REFERENCES}

1 Standard for the diagnosis and care of patients with chronic obstructive pulmonary disease. American Thoracic
Society. 1995. Am J Respir Crit Care Med 1995; 152: Suppl. 5 , S77-S120.

2 Pauwels R. COPD: the scope of the problem in Europe. Chest 2000; 117: Suppl. 2, 332S-335S.

3 Petty TL. Scope of the COPD problem in North America: early studies of prevalence and NHANES III data: basis for early identification and intervention. Chest 2000; 117: Suppl. 2, 326S-331S.

4 Barnes PJ, Shapiro SD, Pauwels RA. Chronic obstructive pulmonary disease: molecular and cellular mechanisms. Eur Respir J 2003; 22: 672-688.

5 Belvisi MG, Bottomley KM. The role of matrix metalloproteinases (MMPs) in the pathophysiology of chronic obstructive pulmonary disease (COPD): a therapeutic role for inhibitors of MMPs? Inflamm Res 2003; 52: 95-100.

6 Russell RE, Culpitt SV, DeMatos C, et al. Release and activity of matrix metalloproteinase- 9 and tissue inhibitor of metalloproteinase- 1 by alveolar macrophages from patients with chronic obstructive pulmonary disease. Am J Respir Cell Mol Biol 2002; 26: 602-609.

7 Molet S, Belleguic C, Léna $\mathrm{H}$, et al. Increase in macrophage elastase (MMP-12) in lungs from patients with chronic obstructive pulmonary disease. Inflamm Res 2005; 54: 31-36.

8 Hautamaki RD, Kobayashi DK, Senior RM, Shapiro SD. Requirement for macrophage elastase for cigarette smokeinduced emphysema in mice. Science 1997; 277: 2002-2004.

9 Jones PW, Willits LR, Burge PS, Calverley PM, Inhaled steroids in obstructive lung disease in Europe study investigators. Disease severity and the effect of fluticasone propionate on chronic obstructive pulmonary disease exacerbations. Eur Respir J 2003; 21: 68-73.

10 Loppow D, Schleiss MB, Kanniess F, Taube C, Jorres RA, Magnussen $\mathrm{H}$. In patients with chronic bronchitis a four week trial with inhaled steroids. Respir Med 2001; 95: 115-121.

11 Keatings VM, Collins PD, Scott DM, Barnes PJ. Differences in interleukin- 8 and tumour necrosis factor alpha in induced sputum from patients with chronic obstructive pulmonary disease or asthma. Am J Respir Crit Care Med 1996; 153: 530-534.

12 Culpitt SV, Maziak W, Loukidis S, Nightingale JA, Matthews JL, Barnes PJ. Effect of high dose inhaled steroid on cells, cytokines, and proteases in induced sputum in chronic obstructive pulmonary disease. Am J Respir Crit Care Med 1999; 160: 1635-1639.

13 Tashkin DP, Altose MD, Connett JE, Kanner RE, Lee WW, Wise RA. Methacholine reactivity predicts changes in lung function over time in smokers with early chronic obstructive pulmonary disease. The Lung Health Study Research Group. Am J Respir Crit Care Med 1996; 153: 1802-1811.

14 Barnette MS, Christensen SB, Essayan DM, et al. SB 207499 (Ariflo), a potent and selective second-generation phosphodiesterase 4 inhibitor: in vitro anti-inflammatory actions. J Pharmacol Exp Ther 1998; 284: 420-426.

15 Gamble E, Grootendorst DC, Brightling CE, et al. Antiinflammatory effects of the phosphodiesterase-4 inhibitor cilomilast (Ariflo) in chronic obstructive pulmonary disease. Am J Respir Crit Care Med 2003; 168: 976-982.

16 Compton $\mathrm{CH}, \mathrm{Gubb} \mathrm{J}$, Nieman $\mathrm{R}$, et al. Cilomilast, a selective phosphodiesterase- 4 inhibitor for treatment of patients with chronic obstructive pulmonary disease: a randomised, dose-ranging study. Lancet 2001; 358: 265-270. 
17 Burge PS, Calverley PM, Jones PW, Spencer S, Anderson JA. Prednisolone response in patients with chronic obstructive pulmonary disease: results from the ISOLDE study. Thorax 2003; 58: 654-658.

18 Corbel M, Germain N, Lanchou J, et al. Selective phosphodiesterase type 4 inhibitor, RP 73401 reduced matrix metalloproteinase 9 activity and TGF- $\beta$ release in acute lung injury in mice: role of the balance between TNF$\alpha$ and IL-10. J Pharmacol Exp Ther 2002; 301: 258-265.

19 Hattotuwa KL, Gizycki MJ, Ansari TW, Jeffery PK, Barnes NC. The effects of inhaled fluticasone on airway inflammation in chronic obstructive pulmonary disease: a double-blind, placebo-controlled biopsy study. Am J Respir Crit Care Med 2002; 165: 1592-1596.

20 Gizycki MJ, Hattotuwa KL, Barnes N, Jeffery PK. Effects of fluticasone propionate on inflammatory cells in COPD: an ultrastructural examination of endobronchial biopsy tissue. Thorax 2002; 57: 799-803.

21 Hogg JC, Wright JL, Wiggs BR, Coxson HO, Opazo SA, Pare PD. Lung structure and function in cigarette smokers. Thorax 1994; 49: 473-478.

22 Baggiolini M, Dewald B, Moser B. Interleukin-8 and related chemotactic cytokines: $\mathrm{CXC}$ and $\mathrm{CC}$ chemokines. Adv Immunol 1994; 55: 97-179.

23 Thompson AB, Daughton D, Robbins RA, Ghafouri MA, Oehlerking M, Rennard SI. Intraluminal airway inflammation in chronic bronchitis: characterization and correlation with clinical parameters. Am Rev Respir Dis 1989; 140: 1527-1537.
24 Lacoste JY, Bousquet J, Chanez P, et al. Eosinophilic and neutrophilic inflammation in asthma, chronic bronchitis, and chronic obstructive pulmonary disease. J Allergy Clin Immunol 1993; 92: 537-548.

25 Finlay GA, Russell KJ, McMahon KJ, et al. Elevated levels of matrix metalloproteinases in bronchoalveolar lavage fluid of emphysematous patients. Thorax 1997; 52: 502-506.

26 Corbel M, Théret N, Caulet-Maugendre S, et al. Repeated endotoxin exposure induces interstitial fibrosis associated with enhanced gelatinase (MMP-2 and MMP-9) activity. Inflamm Res 2001; 50: 129-135.

27 Valença SS, Da Hora K, Castro P, Moraes VG, Carvalho L, Porto LC. Emphysema and metalloelastase expression in mouse lung induced by cigarette smoke. Toxicol Pathol 2004; 32: 351-356.

28 Churg A, Zay K, Shay S, et al. Acute cigarette smokeinduced connective tissue breakdown requires both neutrophils and macrophage metalloelastase in mice. Am Respir Cell Mol Biol 2002; 27: 368-374.

29 Profita M, Chiappara G, Mirabella F, et al. Effect of cilomilast (Ariflo) on TNF-alpha, IL-8, and GM-CSF release by airway cells of patients with COPD. Thorax 2003; 58: 573-579.

30 Lagente V, Martin-Chouly C, Boichot E, Martins MA, Silva PMR. Selective PDE4 inhibitors as potent antiinflammatory drugs for the treatment of airway diseases. Mem Inst Oswaldo Cruz 2005; 100: 131-136.

31 Adcock IM, Lane SJ. Corticosteroid-insensitive asthma: molecular mechanisms. J Endocrinol 2003; 178: 347-355. 